\title{
Memantine Preferentially Blocks Extrasynaptic over Synaptic NMDA Receptor Currents in Hippocampal Autapses
}

\author{
Peng Xia, Huei-sheng Vincent Chen, Dongxian Zhang, and Stuart A. Lipton \\ Del E. Webb Center for Neuroscience, Aging, and Stem Cell Research, Sanford-Burnham Medical Research Institute, La Jolla, California 92037
}

\begin{abstract}
Glutamate is the major excitatory neurotransmitter in the brain. The NMDA subtype of glutamate receptors (NMDAR) is known to mediate many physiological neural functions. However, excessive activation of NMDARs contributes to neuronal damage in various acute and chronic neurological disorders. To avoid unwanted adverse side effects, blockade of excessive NMDAR activity must therefore be achieved without affecting its physiological function. Memantine, an adamantane derivative, has been used for the treatment of Alzheimer's disease with an excellent clinical safety profile. We previously showed that memantine preferentially blocked neurotoxicity mediated by excessive NMDAR activity while relatively sparing normal neurotransmission, in part because of its uncompetitive antagonism with a fast off-rate. Here, using rat autaptic hippocampal microcultures, we show that memantine at therapeutic concentrations (1-10 $\mu \mathrm{M})$ preferentially blocks extrasynaptic rather than synaptic currents mediated by NMDARs in the same neuron. We found that memantine blocks extrasynaptic NMDAR-mediated currents induced by bath application of $100 \mu \mathrm{M}$ NMDA/10 $\mu \mathrm{m}$ glycine with a twofold higher potency than its blockade of the NMDAR component of evoked EPSCs (EPSCs ${ }_{\text {NMDAR }}$ ); this effect persists under conditions of pathological depolarization in the presence of $1 \mathrm{~mm}$ extracellular $\mathrm{Mg}^{2+}$. Thus, our findings provide the first unequivocal evidence to explain the tolerability of memantine based on differential extrasynaptic/synaptic receptor blockade. At therapeutic concentrations, memantine effectively blocks excessive extrasynaptic NMDAR-mediated currents, while relatively sparing normal synaptic activity.
\end{abstract}

\section{Introduction}

Excessive activation of ionotropic glutamate receptors by excitatory amino acids, such as glutamate, is thought to contribute to many neurological diseases, ranging from acute hypoxicischemic brain injury to chronic neurodegenerative diseases such as Alzheimer's, Parkinson's, and Huntington's diseases, HIVassociated neurocognitive disorders, and amyotrophic lateral sclerosis (Choi, 1988; Lipton and Rosenberg, 1994; Lipton, 2006). In many CNS areas, the predominant form of this neurotoxicity appears to be mediated by overactivation of the NMDA subtype of glutamate receptor (NMDAR) and subsequent influx of excessive $\mathrm{Ca}^{2+}$ (Rothman and Olney, 1986; Choi et al., 1988; Chen et al., 1992). Since physiological NMDAR activity is very important for normal brain function in the nervous system, whereas receptor overstimulation contributes to disease states, blockade of excessive NMDAR activity must be achieved without interference of physiological function. High-affinity NMDAR antagonists are effective at NMDAR blockade, but toxic to neurons and produce

Received May 14, 2010; revised June 28, 2010; accepted July 2, 2010.

This work was supported in part by National Institutes of Health Grants R01 EY05477, R01 EY09024, and P01 HD29587 (S.A.L.), and by American Heart Association Fellowship 09P0ST2120061 (P.X.). We thank Traci Fang Newmeyer for technical assistance and Dr. Scott McKercher for helping with this manuscript.

Correspondence should be addressed to Stuart A. Lipton, Del E. Webb Center for Neuroscience, Aging, and Stem Cell Research, Sanford-Burnham Medical Research Institute, La Jolla, CA 92037. E-mail: slipton@ sanfordburnham.org.

D0I:10.1523/JNEUROSCI.2488-10.2010

Copyright $\odot 2010$ the authors $\quad 0270-6474 / 10 / 3011246-05 \$ 15.00 / 0$ neurobehavioral side effects at least in part because they block normal synaptic activity (Lipton, 1993; Rogawski, 1993; Rogawski and Wenk, 2003). In contrast, studies in our laboratory and subsequently others have shown that the adamantane derivative, memantine, preferentially blocks excessive NMDAR activity without disrupting physiological synaptic activity (Chen et al., 1992, 1998; Léveillé et al., 2008; Papadia et al., 2008; Okamoto et al., 2009). Memantine, at low micromolar concentrations, accomplishes this through its action as a low-affinity, uncompetitive, open-channel blocker with a relatively rapid off-rate from the channel (Chen and Lipton, 1997; Lipton, 2006, 2007). Phase 3 clinical trials have shown that memantine is effective in treating moderate-to-severe Alzheimer's disease while being well tolerated at doses that yield concentrations at the receptor approaching $10 \mu \mathrm{M}$ (Reisberg et al., 2003; Tariot et al., 2004; Chen and Lipton, 2006; Okamoto et al., 2009).

The molecular mechanism underlying the clinical tolerability of memantine, however, remains somewhat contentious (Lipton, 1993; Rogawski and Wenk, 2003; Lipton and Chen, 2004; Lipton, 2006, 2007). According to its kinetics of interaction with NMDAR channels, we have predicted that memantine predominantly acts as an open-channel blocker in the presence of prolonged elevation of glutamate concentration (on the scale of minutes or longer), but is relatively inactive when glutamate is elevated for only milliseconds, as in synaptic transmission (Chen and Lipton, 1997; Lipton, 2006, 2007). We and others have previously shown that, unlike other NMDAR antagonists, meman- 
tine appears to be effective in blocking excessive extrasynaptic NMDAR activation by bath-applied NMDA, but less effective on synapses (Chen et al., 1992, 1998; Okamoto et al., 2009). Here, we directly quantify this phenomenon and for the first time show distinctive effects of low micromolar concentrations of memantine on synaptic and extrasynaptic NMDARs in the same preparation, the hippocampal autaptic neuron. We demonstrate that low concentrations of memantine act as an effective antagonist of excessive extrasynaptic NMDAR stimulation while manifesting much less effect on NMDAR-mediated synaptic activity.

\section{Materials and Methods}

Cell culture. Sprague Dawley rat pups of both genders were killed on postnatal day 0 to harvest hippocampal cells for generation of microisland cultures (Segal and Furshpan, 1990; Segal, 1991). This method was used to grow single, isolated excitatory hippocampal neurons that form autapses in culture. Briefly, a $0.15 \%$ agarose solution was spread thinly on $12 \mathrm{~mm}$ coverslips in $35 \mathrm{~mm}$ dishes and allowed to dry. Then a glass microatomizer (Kontes Glass) was used to spray onto the agarose a fine mist of a $17 \mathrm{~mm}$ acetic acid solution containing collagen at $0.0625 \mathrm{mg} / \mathrm{ml}$ and poly-D-lysine at $0.05 \mathrm{mg} / \mathrm{ml}$ (Sigma-Aldrich) to produce "collagen dots" on the agarose base. Hippocampal neurons were dissociated and plated onto the coated coverslips at $4-8 \times 10^{4}$ cells per dish.

Electrophysiology. EPSCs were recorded under voltage clamp from solitary neurons using a patch electrode after $13 \mathrm{~d}$ in vitro. Whole-cell recordings were performed with a cesium chloride-rich intracellular solution. Series resistance was compensated $70-80 \%$ using multiclamp $700 \mathrm{~A}$ patch-clamp amplifier circuitry (Molecular Devices). Currents were acquired using a Digidata 1322 interface and pClamp 10.1 software. All recordings were made at room temperature at a holding potential $\left(V_{\mathrm{h}}\right)$ of -25 or $-70 \mathrm{mV}$. EPSCs were evoked from $V_{\mathrm{h}}=-70 \mathrm{mV}$ at a stimulation rate of $0.1 \mathrm{~Hz}$ by stepping to $+80 \mathrm{mV}$ for $1 \mathrm{~ms}$; from $V_{\mathrm{h}}=-25 \mathrm{mV}$, the neurons were first subjected to a hyperpolarizing prepulse to $-70 \mathrm{mV}$ for $3 \mathrm{~s}$ to remove $\mathrm{Na}^{+}$channel inactivation, and then returned to $-25 \mathrm{mV}$ to elicit an EPSC. Currents were digitally sampled at $10-20 \mathrm{kHz}$ and filtered at $2 \mathrm{kHz}$. The extracellular solution contained the following (in mM): $137 \mathrm{NaCl}, 1 \mathrm{NaHCO}_{3}, 0.34 \mathrm{Na}_{2} \mathrm{HPO}_{4}$, $5.36 \mathrm{KCl}, 0.44 \mathrm{KH}_{2} \mathrm{PO}_{4}, 3 \mathrm{CaCl}_{2}, 5 \mathrm{HEPES}, 22.2$ glucose, 0.01 glycine, 0.003 strychnine, $\mathrm{pH}$ adjusted to 7.2. The intracellular solution contained the following (in $\mathrm{mm}$ ): $120 \mathrm{CsCl}, 20$ tetraethylammonium chloride, 10 HEPES, 2.25 EGTA, $1 \mathrm{CaCl}_{2}, 2 \mathrm{MgCl}_{2}, 4 \mathrm{MgATP}, 0.3 \mathrm{GTP}, 10$ phosphocreatine, $\mathrm{pH}$ adjusted to 7.2 .

Strategy for studying synaptic versus extrasynaptic NMDARs. To assess the effect of memantine on synaptic and extrasynaptic NMDARs in the same neuron, we used microcultured autaptic neurons. Initially, synaptic responses were induced by short-term depolarizations, stable responses were achieved, and then the effect of drug on EPSCs was assessed. Next, taking advantage of the irreversible effect of (+)-5-methyl-10,11dihydro-5H-dibenzo $[a, d]$ cyclohepten-5,10-imine maleate (MK-801), we blocked synaptic NMDARs by repeated synaptic stimulation in the presence of 1-10 $\mu \mathrm{M}$ MK-801. Under these conditions, extrasynaptic NMDARs are spared from blockade (Hardingham et al., 2002; Papadia et al., 2008; Okamoto et al., 2009). Thus, we could then test the effect of memantine on pure extrasynaptic NMDAR-mediated responses induced by bath application of NMDA $(100 \mu \mathrm{M})$ in conjunction with coagonist glycine $(10 \mu \mathrm{M})$. Considering peak responses, the relative ratio of the synaptic to extrasynaptic current in these autaptic neurons was $8.4 \pm 1.0$ $(n=18)$. However, this calculation may underestimate the value for the extrasynaptic current since we did not use saturating concentrations of NMDA. Similarly, the effect of memantine on extrasynaptic responses (vs synaptic responses) may have been underestimated for the same reason since memantine is an uncompetitive antagonist (i.e., at a fixed concentration, the antagonist blocks higher concentrations of NMDA to a relatively greater extent since the action of the antagonist is contingent on previous activation of the receptor by the agonist).
A

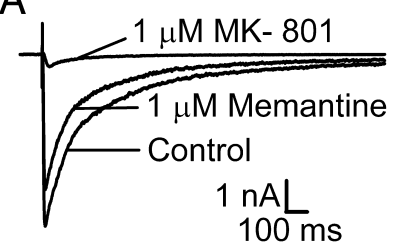

B

C

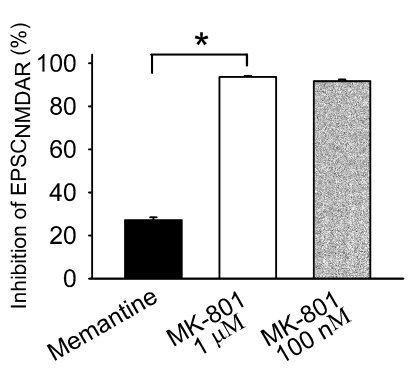

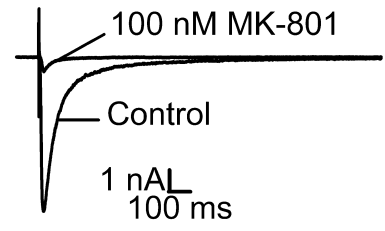

D

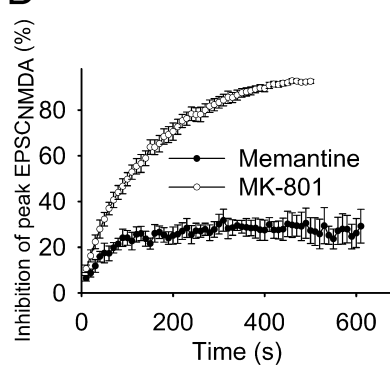

Figure 1. Low micromolar concentrations of memantine manifest relatively little effect on synaptic NMDAR-mediated currents. $\boldsymbol{A}$, At $1 \mu \mathrm{m}$, memantine exerted a minimal effect on the NMDAR component of the EPSC. For comparison, nearly complete blockade by $1 \mu \mathrm{M}$ MK- 801 is shown. $\boldsymbol{B}$, At $100 \mathrm{~nm}, \mathrm{MK}-801$ also nearly completely blocked synaptic NMDARs. $\boldsymbol{C}$, After the inhibitory effect reached a plateau, $1 \mu$ m memantine blocked only $27.1 \pm 13 \%$ of the NMDARmediated component of the EPSC, whereas equimolar MK-801 rendered virtually complete blockade $(93.6 \pm 0.5 \%)$. To reach a plateau with $100 \mathrm{~nm}$ MK-801, we performed prolonged recordings and still observed $91.6 \pm 0.7 \%$ blockade of synaptic currents; 10 nм MK-801, although not reaching a plateau, also blocked nearly all of the EPSC ${ }_{\text {NMDAR }}$ (data not shown). D, At $1 \mu \mathrm{M}$, memantine blockade of the NMDAR-mediated component of the EPSC reached a plateau within $100 \mathrm{~s}$, whereas $1 \mu \mathrm{M}$ MK-801 required $\sim 500 \mathrm{~s}$. Electrical pulses to elicit EPSCs were delivered every $10 \mathrm{~s}$. Values are mean \pm SEM, measured at peak current $\left(n=28 ;{ }^{*} p<0.0001\right.$ by $t$ test).

\section{Results}

\section{Minimal effect of low micromolar concentrations of} memantine on synaptic NMDARs of autaptic neurons

Using the whole-cell configuration of the patch-clamp technique, we recorded the NMDAR component of the EPSC from autapses of solitary hippocampal neurons. The NMDAR component was isolated by suppressing the AMPA receptor-mediated component of the EPSC with $10 \mu \mathrm{M}$ NBQX (2,3-dihydroxy-6-nitro-7sulfamoyl-benzo[f]quinoxaline-2,3-dione). Depolarization of the neuron to $+80 \mathrm{mV}$ for $1 \mathrm{~ms}$ from a holding potential of -70 $\mathrm{mV}$ evoked robust excitatory autaptic NMDAR-mediated currents. Memantine $(1 \mu \mathrm{M})$ blocked $27.1 \pm 1.3 \%$ of the NMDAR component of the EPSC under these conditions after the inhibitory effect had reached a plateau (Fig. 1).

In contrast, previous studies have shown that MK- 801 blocks virtually all of the NMDAR-mediated synaptic current after multiple stimuli, reflecting its use-dependent and irreversible characteristics (Huettner and Bean, 1988; Rosenmund et al., 1993; Hardingham et al., 2002; Papadia et al., 2008; Okamoto et al., 2009). In line with these findings, here in the hippocampal autaptic preparation, a similar concentration of MK-801 (1 $\mu \mathrm{M})$ blocked $93.6 \pm 0.5 \%$ of this current $(n=9 ; p<0.001)$. Nonetheless, this might be considered an unfair comparison since the affinity of MK-801 is so much higher (in the low nanomolar range) than that of memantine (low micromolar). Although MK801 has a much slower off-rate and thus higher apparent affinity for NMDAR-associated channels than memantine, the rate constant for macroscopic blockade (or on-rate) is relatively slow for both drugs (MacDonald et al., 1991; Chen and Lipton, 1997). This fact limits how low a concentration of MK-801 can be as- 
A

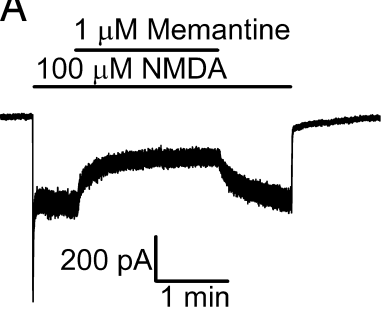

C

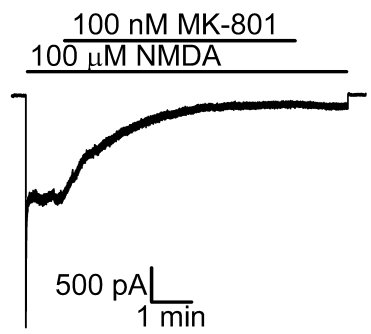

B
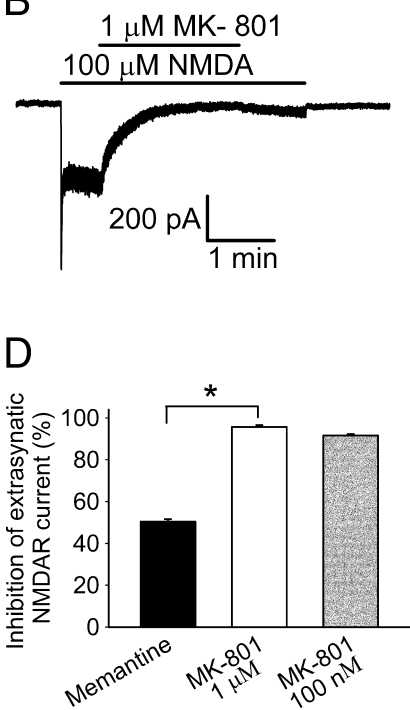

Figure 2. Memantine block of extrasynaptic NMDARs activated by bath application of 100 $\mu \mathrm{M}$ NMDA. $\boldsymbol{A}, \boldsymbol{B}$, Inhibitory effect of $1 \mu \mathrm{m}$ memantine or MK-801 on NMDA-induced extrasynaptic currents at a holding potential of -70 mV.C, At 100 nM, MK-801 also completely blocked extrasynaptic NMDARs. D, Memantine blocked predominantly extrasynaptic NMDAR-mediated current $(50.4 \pm 1.3 \%)$ compared with synaptic NMDARs $(27.1 \pm 1.3 \%)$, whereas MK-801 blocked both equally well regardless of concentration ( $~ 96 \%$ block by $1 \mu \mathrm{m}$ and $\sim 92 \%$ at 100 nм). Values are mean $\pm \operatorname{SEM}\left(n=28 ;{ }^{*} p<0.0001\right)$

sessed electrophysiologically because of the lengthy time required to reach plateau conditions at very low concentration. When we repeated this experiment with $100 \mathrm{~nm}$ MK-801, we still found virtually complete blockade of synaptic responses (Fig. $1 B, C$ ). We also attempted this experiment with 1-10 nM MK-801, but as reported previously (Huettner and Bean, 1988), the on-rate of MK801 is so slow at these concentrations that, although we still saw substantial block of synaptic responses, the extent of inhibition did not reach a plateau in the course of even long recording sessions lasting several tens of minutes. Importantly, however, compared with low nanomolar concentrations of MK-801, micromolar memantine relatively spared synaptic NMDAR function.

\section{Low micromolar concentrations of memantine block extrasynaptic NMDAR-mediated currents}

Since MK-801 almost completely and irreversibly blocks synaptic NMDAR currents under our experimental conditions, we could isolate extrasynaptic NMDAR currents by preapplying MK-801 during repetitive electrical stimulation to activate and subsequently block the autaptic/synaptic currents (see Materials and Methods) (Hardingham et al., 2002; Okamoto et al., 2009). We then tested in the same neuron the effect of memantine on extrasynaptic NMDARs. We activated extrasynaptic NMDARs by bath application of $100 \mu \mathrm{M}$ NMDA plus $10 \mu \mathrm{M}$ glycine; $1 \mu \mathrm{M}$ memantine inhibited approximately one-half of the extrasynaptic NMDAR-mediated current at a holding potential of $-70 \mathrm{mV}(50.4 \pm 1.3 \% ; n=24)$ (Fig. $2 A)$. As a comparison, $1 \mu \mathrm{M}$ MK-801 blocked $95.7 \pm 0.9 \%$ of the NMDA-induced extrasynaptic current using the same paradigm, and $100 \mathrm{~nm}$ blocked $91.6 \pm 0.7 \%$ (Fig. $2 B-D$ ).

\section{Memantine preferentially blocks extrasynaptic over synaptic NMDARs}

We compared the synaptic and extrasynaptic effects of NMDAR open-channel blockers on the same autaptic neuron and found that $1 \mu \mathrm{M}$ memantine blocked extrasynaptic more than synaptic

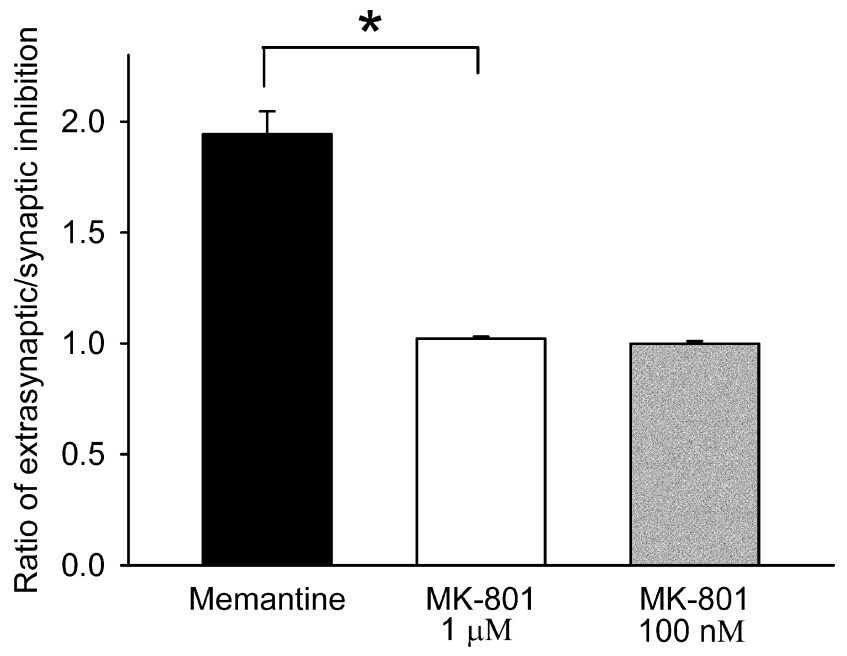

Figure 3. Memantine preferentially blocks extrasynaptic NMDARs. A low $(1 \mu \mathrm{m})$ concentration of memantine blocked extrasynaptic over synaptic NMDARs at a ratio of $\sim 2: 1$, whereas 1 $\mu \mathrm{m}$ or $100 \mathrm{~nm}$ MK-801 blocked both synaptic and extrasynaptic NMDARs equally. Values are mean $\pm \operatorname{SEM}\left(n=28 ;{ }^{*} p<0.0001\right)$.

NMDARs by approximately twofold (1.94 $\pm 0.10 ; n=24)$ (Fig. 3 ). Thus, in the same neuron, low micromolar concentrations of memantine preferentially block extrasynaptic NMDARs, while relatively sparing physiological synaptic function. As a comparison, concentrations of MK-801 of $1 \mu \mathrm{M}$ or $100 \mathrm{nM}$ showed no preference, blocking both synaptic and extrasynaptic NMDARs approximately equally (1.02 \pm 0.01 and $1.00 \pm 0.01 ; n=12$ ) (Fig. 3 ).

\section{Memantine preferentially blocks extrasynaptic over synaptic NMDARs under pathological conditions}

Under normal conditions, at resting membrane potentials, most NMDARs are blocked by extracellular $\mathrm{Mg}^{2+}$, which occupies the channel (Mayer et al., 1984; Nowak et al., 1984; Dingledine et al., 1999; Chen and Lipton, 2006). Under pathological conditions, however, cells continue to depolarize until $\mathrm{Mg}^{2+}$ is repelled, and $\mathrm{Mg}^{2+}$ block is mostly relieved (Zeevalk and Nicklas, 1992; Chen and Lipton, 2006). It has been reported that memantine blockade is less voltage dependent than $\mathrm{Mg}^{2+}$, so memantine can still block NMDARs effectively under relatively depolarized conditions (Wrighton et al., 2008). Thus, we next tested the effect of memantine on synaptic and extrasynaptic NMDAR-mediated currents in the presence of $1 \mathrm{~mm} \mathrm{Mg}^{2+}$ at a holding potential of $-25 \mathrm{mV}$, which mimics severe neuropathological conditions. In these experiments with relatively depolarized holding potentials, we tested a concentration of $10 \mu \mathrm{M}$ memantine because we recently showed that this was the concentration that was effectively present at NMDAR-operated channels in previous rodent studies as well as human clinical trials of the drug under pathological conditions (Chen and Lipton, 1997; Lipton, 2006; Okamoto et al., 2009). In this paradigm, to monitor synaptic currents the neurons received a brief hyperpolarizing prepulse to remove $\mathrm{Na}^{+}$ channel inactivation and then returned to $-25 \mathrm{mV}$ to elicit an EPSC (for details, see Materials and Methods).

Memantine $(10 \mu \mathrm{M})$ blocked $39.8 \pm 2.5 \%$ of the NMDARmediated component of EPSCs in the presence of $1 \mathrm{mM} \mathrm{Mg}^{2+}$, whereas the same concentration of memantine blocked $64.3 \pm$ $2.5 \%$ of the extrasynaptic NMDAR current in the same neuron (Fig. 4). Thus, under pathological conditions, when NMDARs are overactivated and $\mathrm{Mg}^{2+}$ is repelled from the channels because 


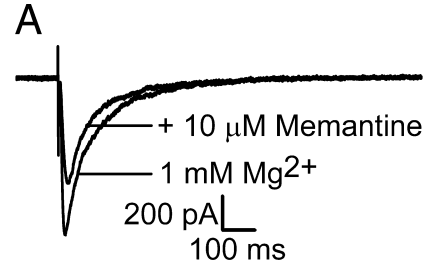

B
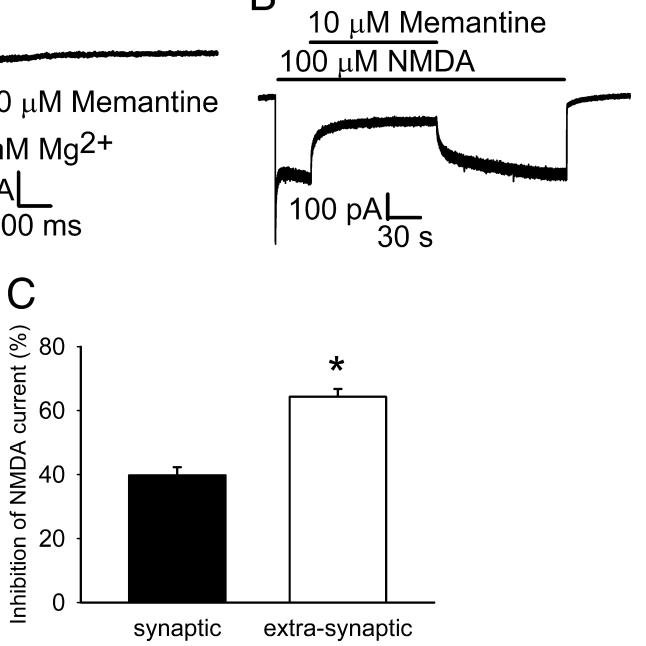

Figure 4. Therapeutic concentrations of memantine block pathological NMDA-induced currents. $A$, At $10 \mu \mathrm{M}$, memantine exerted a minimal effect on the NMDAR-mediated component of the EPSC at a holding potential of $-25 \mathrm{mV}$ in the presence of $1 \mathrm{~mm}$ extracellular $\mathrm{Mg}^{2+}$. $\boldsymbol{B}$, Under the same conditions, $10 \mu \mathrm{m}$ memantine displayed a substantial inhibitory effect on 100 $\mu \mathrm{m}$ NMDA-induced extrasynaptic currents. $\boldsymbol{C}$, Memantine $(10 \mu \mathrm{m})$ significantly blocked more extrasynaptic than synaptic NMDAR-mediated currents when neurons were pathologically depolarized $\left(V_{\mathrm{h}}=-25 \mathrm{mV}\right.$; extrasynaptic inhibition, $64.3 \pm 2.5 \%$; synaptic inhibition, $39.8 \pm$ $2.5 \% ; n=7 ;{ }^{*} p<0.0005$ by paired $t$ test). Values are mean \pm SEM.

of depolarization, memantine still exhibits preferential blockade of extrasynaptic over synaptic NMDAR-mediated currents.

\section{Discussion}

Excessive activation of NMDARs by excitatory amino acids such as glutamate may contribute to neuronal damage in a number of neurological disorders (Rothman and Olney, 1986; Choi et al., 1988; Lipton and Rosenberg, 1994). Recently, Hardingham and colleagues have demonstrated that activation of synaptic versus extrasynaptic NMDARs induces opposite effects on various cellular pathways, including CREB (cAMP response elementbinding protein)/CBP (CREB-binding protein) transcriptional events that trigger the neuroprotective PGC- $1 \alpha$ pathway and antioxidant cascades (Hardingham et al., 2002; Lipton, 2008; Papadia et al., 2008). Physiological stimulation of synaptic NMDARs activates these neuronal survival pathways, whereas excessive stimulation of extrasynaptic NMDARs leads to the loss of mitochondrial membrane potential, inhibition of survival cascades, and activation of cell death pathways. Additionally, we and colleagues have recently shown that neurodegenerative disorders characterized by protein misfolding may also be influenced by electrical activity, with extrasynaptic NMDARs mediating formation of toxic soluble oligomers of aberrant proteins, whereas synaptic activity favors the "walling off" of misfolded proteins into less toxic macroscopic aggregates (Okamoto et al., 2009). Hence, an important strategy for potential therapeutic yet clinically tolerated NMDAR antagonists would be to block excessive extrasynaptic currents while relatively sparing synaptic activity. Such maintenance of normal neurotransmission would also minimize undesirable side effects caused by disrupting physiological activity.

The hippocampal autaptic neuronal preparation afforded us the opportunity to make an unequivocal quantitative comparison of the effect of NMDAR antagonists on synaptic versus extrasynaptic receptors by recording from "the same cell" under identical conditions. Memantine at low micromolar concentrations is clinically tolerated while offering beneficial effects in pa- tients with moderate-to-severe Alzheimer's disease (Wesemann et al., 1980; Hesselink et al., 1999; Danysz et al., 2000; Reisberg et al., 2003; Tariot et al., 2004; Chen and Lipton, 2006; Okamoto et al., 2009). It is thus the only known clinically tolerated NMDAR antagonist. Here, we show that memantine at therapeutic concentrations improves the balance of excitatory activity by preferentially blocking extrasynaptic NMDARs, even under pathologically depolarizing conditions, while relatively sparing synaptic communication. MK-801, which is poorly tolerated clinically (Lipton, 2006, 2007), blocked both synaptic and extrasynaptic NMDARs to the same degree. The fact that low micromolar memantine displays a preference for blocking extrasynaptic over synaptic NMDARs may help explain why memantine manifests a therapeutic effect with few side effects in its clinical use in humans (Lipton, 2006, 2007; Okamoto et al., 2009). That is, memantine relatively spares physiological synaptic transmission important for normal brain function. Extrasynaptic NMDARs, however, which are excessively activated under pathological conditions and harmful to the brain, are effectively antagonized by memantine.

Why does memantine block extrasynaptic more than synaptic NMDARs? The answer to this query could give us hints for future therapeutic drug development, not only for modulation of NMDAR activity but for other targets as well (Lipton, 2006, 2007). There are at least three potential explanations: (1) memantine cannot enter synaptic NMDAR-operated ion channels as readily as those of extrasynaptic NMDARs; (2) synaptic and extrasynaptic NMDARs are composed of different NR2 subunits for which memantine manifests different potencies; (3) disparate activity patterns of synaptic and extrasynaptic NMDAR-operated channels result in a differential degree of memantine blockade. To begin to distinguish between these alternatives, we have applied memantine for long periods of time ( $\geq 10 \mathrm{~min})$ to achieve a plateau of the antagonistic effect, and yet we still obtained differential blockade of synaptic and extrasynaptic receptors, excluding the first explanation. It has been reported that synaptic and extrasynaptic NMDARs are composed of different NR2 subunits, with NR2A predominating at synaptic receptors and NR2B at extrasynaptic NMDARs, at least in mature neurons (Dalby and Mody, 2003; Thomas et al., 2006). We also found that this is indeed the case in our autaptic neuronal cultures (data not shown). Memantine, however, was found to have little preference among these NR2 subunits (Bresink et al., 1996). In the presence of $1 \mathrm{~mm}$ extracellular $\mathrm{Mg}^{2+}, 0.1-1 \mu \mathrm{M}$ memantine was recently shown to exert a more potent effect at NR2C/D subunits than NR2A/B subunits (Kotermanski and Johnson, 2009); however, at $10 \mu \mathrm{M}$, the concentration estimated to be present at the channel mouth after therapeutic dosing [Okamoto et al. (2009), their supplemental information], memantine is quite effective at each NR2 subtype (Kotermanski and Johnson, 2009). Our recent result that the specific binding site for memantine is in the channel region of the NR1 subunit (present in all NMDARs) may explain these previous findings (Chen and Lipton, 2005) and makes the second potential explanation very unlikely as the main mechanism for the safety profile of memantine.

Our results are most compatible with the third explanation (i.e., the known disparate activity patterns of synaptic and extrasynaptic NMDARs result in differential memantine blockade). We previously proposed that, because of its uncompetitive nature and relatively rapid unblocking or "off-rate" from NMDAR-associated channels, memantine predominantly acts as an open-channel blocker in the presence of prolonged elevation of glutamate concentration or prolonged channel activity (on the scale of tens of minutes or longer), as seen for extrasynaptic receptors, but is 
relatively inactive when glutamate is elevated for only milliseconds, as in synaptic transmission (Lipton, 2006, 2007; Wyllie and Chen, 2007; Okamoto et al., 2009). Heretofore, however, it has been difficult to observe the action of known concentrations of memantine at neuronal synapses because of their compact geometry. This experiment was necessary to confirm the fact that synaptic channels are blocked to a lesser extent than extrasynaptic channels by memantine; indeed, we accomplished that objective in the present experiments. Here, we show unequivocally for the first time that memantine indeed preferentially blocks extrasynaptic receptors over synaptic receptors, which may contribute to the clinical tolerability of memantine. Hence, future drug development must attend to the differential blockade of extrasynaptic versus synaptic NMDAR-mediated currents with the goal of achieving a higher ratio of blockade of extrasynaptic/synaptic current, which should lead to even better tolerability and neuroprotective efficacy.

\section{References}

Bresink I, Benke TA, Collett VJ, Seal AJ, Parsons CG, Henley JM, Collingridge GL (1996) Effects of memantine on recombinant rat NMDA receptors expressed in HEK 293 cells. Br J Pharmacol 119:195-204.

Chen HS, Lipton SA (1997) Mechanism of memantine block of NMDAactivated channels in rat retinal ganglion cells: uncompetitive antagonism. J Physiol 499:27-46.

Chen HS, Lipton SA (2005) Pharmacological implications of two distinct mechanisms of interaction of memantine with $\mathrm{N}$-methyl-D-aspartategated channels. J Pharmacol Exp Ther 314:961-971.

Chen HS, Lipton SA (2006) The chemical biology of clinically tolerated NMDA receptor antagonists. J Neurochem 97:1611-1626.

Chen HS, Pellegrini JW, Aggarwal SK, Lei SZ, Warach S, Jensen FE, Lipton SA (1992) Open-channel block of $N$-methyl-D-aspartate (NMDA) responses by memantine: therapeutic advantage against NMDA receptormediated neurotoxicity. J Neurosci 12:4427-4436.

Chen HS, Wang YF, Rayudu PV, Edgecomb P, Neill JC, Segal MM, Lipton SA, Jensen FE (1998) Neuroprotective concentrations of the N-methyl-Daspartate open-channel blocker memantine are effective without cytoplasmic vacuolation following post-ischemic administration and do not block maze learning or long-term potentiation. Neuroscience 86:1121-1132.

Choi DW (1988) Glutamate neurotoxicity and diseases of the nervous system. Neuron 1:623-634.

Choi DW, Koh JY, Peters S (1988) Pharmacology of glutamate neurotoxicity in cortical cell culture: attenuation by NMDA antagonists. J Neurosci 8:185-196.

Dalby NO, Mody I (2003) Activation of NMDA receptors in rat dentate gyrus granule cells by spontaneous and evoked transmitter release. J Neurophysiol 90:786-797.

Danysz W, Parsons CG, Quack G (2000) NMDA channel blockers: memantine and amino-aklylcyclohexanes-in vivo characterization. Amino Acids 19:167-172.

Dingledine R, Borges K, Bowie D, Traynelis SF (1999) The glutamate receptor ion channels. Pharmacol Rev 51:7-61.

Hardingham GE, Fukunaga Y, Bading H (2002) Extrasynaptic NMDARs oppose synaptic NMDARs by triggering CREB shut-off and cell death pathways. Nat Neurosci 5:405-414.

Hesselink MB, De Boer BG, Breimer DD, Danysz W (1999) Brain penetration and in vivo recovery of NMDA receptor antagonists amantadine and memantine: a quantitative microdialysis study. Pharm Res 16:637-642.

Huettner JE, Bean BP (1988) Block of N-methyl-D-aspartate-activated current by the anticonvulsant MK-801: selective binding to open channels. Proc Natl Acad Sci U S A 85:1307-1311.

Kotermanski SE, Johnson JW (2009) $\mathrm{Mg}^{2+}$ imparts NMDA receptor subtype selectivity to the Alzheimer's drug memantine. J Neurosci 29:27742779.

Léveillé F, El Gaamouch F, Gouix E, Lecocq M, Lobner D, Nicole O, Buisson A (2008) Neuronal viability is controlled by a functional relation between synaptic and extrasynaptic NMDA receptors. FASEB J 22:4258-4271.

Lipton SA (1993) Prospects for clinically tolerated NMDA antagonists: open-channel blockers and alternative redox states of nitric oxide. Trends Neurosci 16:527-532.

Lipton SA (2006) Paradigm shift in neuroprotection by NMDA receptor blockade: memantine and beyond. Nat Rev Drug Discov 5:160-170.

Lipton SA (2007) Pathologically activated therapeutics for neuroprotection. Nat Rev Neurosci 8:803-808.

Lipton SA (2008) NMDA receptor activity regulates transcription of antioxidant pathways. Nat Neurosci 11:381-382.

Lipton SA, Chen HS (2004) Paradigm shift in neuroprotective drug development: clinically tolerated NMDA receptor inhibition by memantine. Cell Death Differ 11:18-20.

Lipton SA, Rosenberg PA (1994) Excitatory amino acids as a final common pathway for neurologic disorders. N Engl J Med 330:613-622.

MacDonald JF, Bartlett MC, Mody I, Pahapill P, Reynolds JN, Salter MW, Schneiderman JH, Pennefather PS (1991) Actions of ketamine, phencyclidine and MK-801 on NMDA receptor currents in cultured mouse hippocampal neurones. J Physiol 432:483-508.

Mayer ML, Westbrook GL, Guthrie PB (1984) Voltage-dependent block by $\mathrm{Mg}^{2+}$ of NMDA responses in spinal cord neurones. Nature 309:261-263.

Nowak L, Bregestovski P, Ascher P, Herbet A, Prochiantz A (1984) Magnesium gates glutamate-activated channels in mouse central neurones. Nature 307:462-465.

Okamoto S, Pouladi MA, Talantova M, Yao D, Xia P, Ehrnhoefer DE, Zaidi R, Clemente A, Kaul M, Graham RK, Zhang D, Vincent Chen HS, Tong G, Hayden MR, Lipton SA (2009) Balance between synaptic versus extrasynaptic NMDA receptor activity influences inclusions and neurotoxicity of mutant huntingtin. Nat Med 15:1407-1413.

Papadia S, Soriano FX, Léveillé F, Martel MA, Dakin KA, Hansen HH, Kaindl A, Sifringer M, Fowler J, Stefovska V, McKenzie G, Craigon M, Corriveau R, Ghazal P, Horsburgh K, Yankner BA, Wyllie DJ, Ikonomidou C, Hardingham GE (2008) Synaptic NMDA receptor activity boosts intrinsic antioxidant defenses. Nat Neurosci 11:476-487.

Reisberg B, Doody R, Stöffler A, Schmitt F, Ferris S, Möbius HJ (2003) Memantine in moderate-to-severe Alzheimer's disease. N Engl J Med 348: 1333-1341.

Rogawski MA (1993) Therapeutic potential of excitatory amino acid antagonists: channel blockers and 2,3-benzodiazepines. Trends Pharmacol Sci 14:325-331.

Rogawski MA, Wenk GL (2003) The neuropharmacological basis for the use of memantine in the treatment of Alzheimer's disease. CNS Drug Rev 9:275-308

Rosenmund C, Clements JD, Westbrook GL (1993) Nonuniform probability of glutamate release at a hippocampal synapse. Science 262:754-757.

Rothman SM, Olney JW (1986) Glutamate and the pathophysiology of hypoxic-ischemic brain damage. Ann Neurol 19:105-111.

Segal MM (1991) Epileptiform activity in microcultures containing one excitatory hippocampal neuron. J Neurophysiol 65:761-770.

Segal MM, Furshpan EJ (1990) Epileptiform activity in microcultures containing small numbers of hippocampal neurons. J Neurophysiol 64:1390 1399.

Tariot PN, Farlow MR, Grossberg GT, Graham SM, McDonald S, Gergel I (2004) Memantine treatment in patients with moderate to severe Alzheimer disease already receiving donepezil: a randomized controlled trial. JAMA 291:317-324.

Thomas CG, Miller AJ, Westbrook GL (2006) Synaptic and extrasynaptic NMDA receptor NR2 subunits in cultured hippocampal neurons. J Neurophysiol 95:1727-1734

Wesemann W, Sturm G, Fünfgeld EW (1980) Distribution of metabolism of the potential anti-parkinson drug memantine in the human. J Neural Transm Suppl 143-148.

Wrighton DC, Baker EJ, Chen PE, Wyllie DJ (2008) $\mathrm{Mg}^{2+}$ and memantine block of rat recombinant NMDA receptors containing chimeric NR2A/2D subunits expressed in Xenopus laevis oocytes. J Physiol 586:211-225.

Wyllie DJ, Chen PE (2007) Taking the time to study competitive antagonism. Br J Pharmacol 150:541-551.

Zeevalk GD, Nicklas WJ (1992) Evidence that the loss of the voltagedependent $\mathrm{Mg}^{2+}$ block at the $\mathrm{N}$-methyl-D-aspartate receptor underlies receptor activation during inhibition of neuronal metabolism. J Neurochem 59:1211-1220. 